\title{
Translating preschoolers' game experiences into design guidelines via a laddering study.
}

\author{
Véronique Celis ${ }^{\mathrm{a}}$, Jelle Husson ${ }^{\mathrm{b}}$, Vero Vanden Abeele ${ }^{\mathrm{b}}$, Leen Loyez ${ }^{\mathrm{c}}$, \\ Lieven Van den Audenaeren ${ }^{b}$, Pol Ghesquière ${ }^{a}$, Ann Goeleven ${ }^{c}$, Jan Wouters ${ }^{d}$, Luc Geurts ${ }^{b}$
}

\author{
${ }^{\text {aP }}$ arenting and Special Education Research Unit, KU Leuven, \\ L. Vanderkelenstraat 32 - Box 3765, 3000 Leuven, Belgium, +32 (0)16 3236 37, \\ \{veronique.celis;pol.ghesquiere\}@ppw.kuleuven.be \\ be-Media Lab, Group T - International University College Leuven, \\ Andreas Vesaliusstraat 13, 3000 Leuven, Belgium, +32 (0)16301030, \\ \{jelle.husson;vero.vanden.abeele;lieven.vda;luc.geurts\}@groept.be \\ 'Dept. Speech Language Pathology (MUCLA), University Hospitals Leuven Belgium, \\ Kapucijnenvoer 33, 3000 Leuven, Belgium, +32 (0)16 3323 34, \\ \{leen.loyez;ann.goeleven\}@uzleuven.be \\ ${ }^{\mathrm{d}}$ ExpORL, Department of Neurosciences, KU Leuven, \\ Herestraat49 - Box 721, 3000 Leuven, Belgium, +32 (0)16 3304 75, \\ jan.wouters@med.kuleuven.be
}

\begin{abstract}
Over the past decades, preschoolers emerged as frequent and experienced users of new digital media. As this trend continues, it is important for game designers to address the gratifications of this new gaming audience. Unfortunately, existing theoretical frameworks on meaningful gameplay for preschoolers are rare, outdated, or they lack a comprehensive validation. In this paper, we present a User Experience (UX) Laddering study to unveil the gameplay preferences of preschoolers, relying on five-year olds $(n=25)$ as active research participants. The results of this study provide a set of meaningful and useful guidelines for future game designers, directed at this young target group.
\end{abstract}

\section{Categories and Subject Descriptors}

H.5.2[Information Interfaces And Presentation]:User Interfaces - User-centered design

\section{General Terms}

Design, Human Factors

\section{Keywords}

User Experience, Design Research, Research Methods, Laddering, Preschoolers, Children, Child-centered Design

\section{INTRODUCTION}

Over the past decades we have witnessed the adoption of digital media by younger generations. In particular, games that address a young, even preliterate audience have boomed after the introduction of smartphones and tablet PCs. A recent study

Permission to make digital or hard copies of all or part of this work for personal or classroom use is granted without fee provided that copies are not made or distributed for profit or commercial advantage and that copies bear this notice and the full citation on the first page. To copy otherwise, or republish, to post on servers or to redistribute to lists, requires prior specific permission and/or a fee.

IDC '13, June $24 \quad-272013$, New York, NY, USA Copyright 2013 ACM 978-1-4503-1918-8/13/06 ..\$15.00. reported that 52 percent of all American 0- to 8-year-olds have access to a new mobile device such as a smartphone, video iPod, or tablet (e.g. iPad) [17]. In 2011, almost three-quarters (72\%) of the top selling apps targeted preschool or elementary aged children. Apps for toddlers/preschoolers are thereby the most popular age category (58\%), and experienced the greatest growth since $2009(23 \%)$ [22]. In other words, games for preschoolers are considered as 'big business' and a growing market still. Yet, preschoolers represent a target group that is not easy to grasp in terms of design characteristics. Five-year-olds will not post rants on game forums, fill out gamer surveys or subscribe to game magazines. Nevertheless, in order to design and develop games that are successful, it is imperative that the gaming audience is well understood. This is no different when designing games for preschoolers. Although many insights from developmental psychology on preschool children can be found, these insights tell us little about the wishes and imaginations of these young children before, during and after gameplay. In order to design meaningful play for preschoolers we need to move beyond developmental psychology.

\section{MEANINGFUL PLAY FOR PRESCHOOLERS}

Designing meaningful play is second order design [19]. As a game designer, one can construct a narrative, implement rules and challenges, and define the goals. However, one can never directly design the game experience itself, which is held by the player. In second order design, this game experience is only realized indirectly, through these narrative, rules and challenges. Therefore, Hunicke, Leblanc and Zubek [6] offer game designers the Mechanics-Dynamics-Aesthetics (MDA) framework to bridge the gap between the desired playing experience (or Aesthetics, e.g. fantasy) (see Table 1) and the actual base components of the game (or Mechanics, e.g. algorithms, 3D models). The interaction between the mechanics of the game and the aesthetics of the game results in the Dynamics or "the run-time behavior of the mechanics acting on player inputs and each other's outputs over 
time" [6]. In other words, Mechanics generate Dynamics, which in turn work to create Aesthetic experiences.

Hunicke et al. posit that game designers should firstly understand the aesthetics that the audience is seeking and secondly design the dynamics of the game in function of these targeted aesthetics. Only then designers can produce meaningful mechanics for the player. Hunicke et al. themselves offered eight different aesthetics (see Table 1) that can be addressed via games. However, these aesthetics are formulated for all game players, they do not specifically address young game players.

Table 1. Eight aesthetics provided by the MDA framework[6]

\begin{tabular}{|l|}
\hline 1. Sensation: Game as sense-pleasure \\
\hline 2. Fantasy: Game as make-believe \\
\hline 3. Narrative: Game as drama \\
\hline 4. Challenge: Game as obstacle course \\
\hline 5. Fellowship: Game as social framework \\
\hline 6. Discovery: Game as uncharted territory \\
\hline 7. Expression: Game as self-discovery \\
\hline 8. Submission: Game as pas-time \\
\hline
\end{tabular}

Perhaps, the first well known and comprehensive study on youngsters' video games gratifications ${ }^{1}$ was carried out by Sherry, Lucas, Greenberg and Lachlan [21]. These authors conducted survey studies with young players (ranging from elementary scholars to university students) in order to determine the uses and gratifications of playing video games. They defined six gratifications (see Table 2) that could explain why young people play video games. However, similar to Hunicke et al. this set of motives is still quite general, or abstract for game designers. Guidelines on how to design for these motives (i.e. which dynamics or mechanics) are not given. Moreover, these gratifications were not based on preschoolers, but rather on gamers from elementary school to high school.

Table 2. Six videogames gratifications [21]

\begin{tabular}{|l|}
\hline 1. Competition: to be the best player of the game \\
\hline 2. Challenge: to push yourself to beat the game, progress to next level \\
\hline 3. Social interaction: to play as a social experience withfriends \\
\hline 4. Diversion: to pass time or alleviate boredom \\
\hline 5. Fantasy: to do things that one cannot do in real life \\
\hline 6. Arousal: to play for excitement \\
\hline
\end{tabular}

With respect to preschoolers, Zaman and Vanden Abeele [26,29] put forward a 'likeability framework' (see Figure 1). This framework enumerates playing motives for preschoolers, but in addition puts forward specific 'attributes' to achieve these gratifications. While the gratifications (Challenge \& Control, Social experiences, Fantasy, Creative and constructive expressions, Body \& Senses) are similar to the ones

\footnotetext{
${ }^{1}$ According to Palmgreen and Rayburn, a gratification is " $a$ belief that a certain media behavior has a given desirable outcome for a particular respondent"[11]. Therefore, we can equate gratifications, acquired via Uses and Gratifications research methods, the 'Aesthetics' of the MDA framework.
}

aforementioned by Hunicke et al. and Sherry et al., the attributes associated with their respective gratifications offer more concrete guidelines on how to achieve these gratifications. However, Vanden Abeele and Zaman did not specifically target their framework to games, but to interactive products in general. Moreover, the study was neither validated nor reinforced by other researchers. Finally, we remark that the study dates back to 2006, long before the introduction of tablet PCs and smartphones. In other words, these gratifications and attributes, depicted in the likeability framework, appear to be interesting but might not provide accurate or useful operational guidelines for designing actual media products.

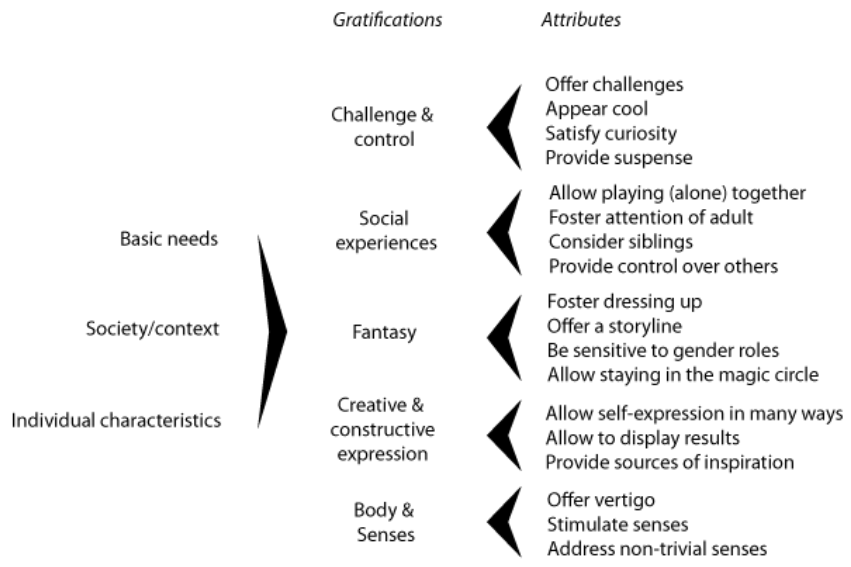

Figure 1. The extended likability framework. Reprinted from [26].

To summarize, the studies described above lack information on how the dynamics and mechanics should be designed to target the desired gratifications of preschoolers. Consequently, the gratifications/aesthetics are perceived as being too abstract in order to offer guidelines for designing games. Moreover, in two studies the gratifications are not focused on games particularly for preschoolers [6,21], and the third study, which does address preschoolers, is outdated and not validated by other researchers [26]. Therefore, we argue that there is a dearth of insights in the specifics of game experiences for preschoolers and the way they can be linked to specific game dynamics and/or game mechanics such as narratives. In this paper we present a study that investigates what is important for preschoolers' game experiences and that translates these results into concrete guidelines for designing digital games for preschoolers.

\section{USER EXPERIENCE LADDERING AS A PLAYER-CENTERED DESIGN METHOD}

Whereas early game design often limited user involvement to play testing at the end of the design and development cycle, usercentered design (UCD) considers the needs, wants, and limitations of end users of a product at each stage of the design process [2, 7]. The audience is involved from the start through several methods, including co-creation where end-users take part in the design 
process, ethnographic studies, focus groups with scenarios, etc. In the past years, we have witnessed the adoption of user-centered design (UCD) principles in the early stages of game design, in order to investigate the aesthetics sought after by the audience.

One specific method that might be particularly useful when working with preschoolers is Laddering. Laddering refers to an indepth, one-on-one interviewing technique, and additionally a specific method for crossing over from qualitative to quantitative data [15]. Laddering has been found valuable for doing user experience research $[8,9]$ and has been proven to work with preschoolers $[25,31]$. Before discussing the Laddering method, we will go briefly into its roots, namely Means-End theory.

The premise of Means-End theory is that users learn to choose a product (or medium) because it contains attributes that are instrumental to achieving desired consequences and fulfilling values. The common generic Means-End chain consists of attributes (A), desired consequences (also called benefits) (C), and values $(\mathrm{V})$ [3]. In consumer research, these Means-End chains are used to explain what motivates consumers to desire certain products or product attributes. Means-End theory provides a theoretical grounding to the Mechanics-Dynamics-Aesthetics framework of Hunicke et al.

As yet mentioned, Means-End analysis is preferably done via laddering [15]. Laddering refers to an in-depth, one-on-one interviewing technique, used to develop an understanding of how users translate the attributes of a product into meaningful associations with the "self". Laddering involves a tailored interviewing format using primarily a series of directed probes, typified by the following question: "Why is that important to you?". The goal is to identify linkages across the range of attributes, consequences, and values. These association networks or ladders, ranging from the concrete (i.e. product attributes) to the abstract (consequences and values), provide an understanding of the relations between a product's attributes and the user motivational perspective to acquire this product. Hence, Laddering not only allows discovering the aesthetics of playing but equally the network of linkages to the underlying attributes. The ultimate result of a Laddering study is an insight into these meaningful linkages across attributes, consequences and values (see Figure 3 for the Hierarchical Value Map of this study).

One specific adaptation to Laddering for analyzing user experiences is UX Laddering[25]. UX Laddering consists of four phases: the product interaction phase, the attribute elicitation phase according to preference ranking, the actual lenient Laddering interview and the data analysis phase). A summary of these four crucial steps of User Experience Laddering is depicted in Figure 2.

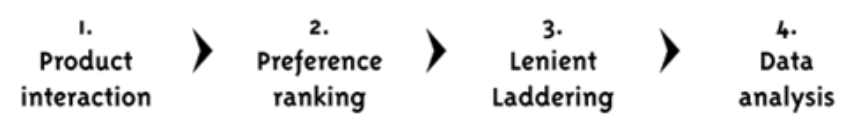

Figure 2. The four steps of UX Laddering

\subsection{Product Interaction}

During the first step of User Experience Laddering, the respondent is asked to explore each of the products one by one for about ten minutes. Typically, two to three alternatives will be presented. This step helps participants situate their usage in a realistic (actual usage) situation. It is certainly key to interactive products, as part of the attributes lie in the interaction itself.

\subsection{Preference Ranking}

The second step of the User Experience Laddering process asks for indicating the preferred alternative(s). While several other methods exist for eliciting attributes and starting up a Laddering interview, preference ranking works particularly well within the UX context. Starting an interview by asking which product participants liked the most and/or the least is a very natural (and useful) way of starting an interview.

\subsection{Lenient Laddering}

The third step is most characteristic of Laddering. From now on, the participants are asked to explain their preference ranking. A typical question addressed to the participants is structured as follows: "Why did you prefer product $\mathrm{X}$ to the alternative product(s)?" Lenient laddering stresses a relaxed and natural interview style, where only the most salient elements that come to the mind of the participant are asked for. When arriving at the psycho-social consequences, the interview has achieved its goals. Values are only noted if mentioned promptly.

\subsection{Data Analysis}

Although many researchers often refer to Laddering as only a special interviewing technique, one might easily forget that full Laddering entails a procedure for data analysis as well[15].The Laddering data analysis process involves a qualitative and a quantitative phase. In the qualitative phase, the Laddering interviews are transcribed and meaningful core elements (i.e., attributes, consequences, values) are coded. This phase relies on skills that are standard in qualitative research and in content analysis. Reliable coding (i.e., interpreting, categorizing and labeling the data while bearing in mind the A-C-V conceptualization), is necessary to define those core elements that emerge from the interviews. Categories of elements need to be broad enough to get replications, i.e. a category must be mentioned by more than one respondent. Yet, these categories should not be so broad that all meaning is lost, i.e. that there is a lack of discrimination between responses. Once the categories of elements are defined and labeled, the individual ladders can be reinspected and decomposed based on these categories.

Next, in the quantitative phase, the data from all individual ladders are summarized and the relations between all elements are quantified in terms of direct links (i.e., between adjacent elements in one ladder) and indirect links (i.e., between non-adjacent elements in one ladder). In order to focus on the most relevant data and to reveal dominant patterns at the aggregate level, the researcher has to decide upon the necessary link strength of direct or indirect links. Links between elements that fall beneath specified cut-off levels are ignored because they are only marginally related; those that reach that predefined level are retained. It is at this point that Laddering crosses over from qualitative data gathering to quantitative data treatment. This is a valuable aspect of the Laddering method, as it resolves the 
contradiction between quantitative and qualitative research methods. Laddering starts off with an exploratory, ground-up research method that allows participants to respond in their own words (enhancing content validity). Next, Laddering utilizes a formalized, structured method for interpreting the data (enhancing generalization).

Finally, an overview of the dominant links between attributes, consequences and values -the Means-End chains at the aggregate level- is typically visualized in a network of associations [15], termed the Hierarchical Value Map (HVM, Figure 3).

Through this insight in the relationships between attributes, consequences and values, researchers can understand the meaning that product attributes bring to users, or the motives that users have for product usage. The real interest of Laddering -as with all Means-End approaches- therefore lies in identifying and understanding the associations between elements, rather than merely deriving an inventory of attributes, consequences or values. Researchers and designers can utilize this association network as a basis for: (1) comparing different scenarios, prototypes, designs, brands or products; (2) understanding the impact of design features on user appreciation; and (3) making informed design decisions taking into account the previous insights.

In this study, we want to involve preschool children as active research participants in user-centered game design, with the aim of formulating meaningful and useful guidelines for future game designers, directed at this specific target group. We are not interested in formulating design guidelines based on the developmental capabilities and limitations of preschoolers, related to memory, attention, perception, motor skills or learning. The focus is not on the production of developmental knowledge with the aim of improving the process of instructional design, development and evaluation. Instead, the intended design guidelines should address more subjective preferences related to social, personal and emotional motives of preschoolers. We aim at revealing these specific motives, by asking preschoolers to describe what they like in different games. Consequently, the resulting guidelines should allow for designing pleasurable, enjoyable and entertaining games

\subsection{Participants/Location}

Twenty-five children (15 boys and 10 girls) were included in the Laddering study. The children were all 3rd grade preschoolers from three different elementary schools in Flemish Brabant, Belgium. Mean age at the time of data collection was 5 years and 6 months (SD $=4$ months). Interviews were administered individually in a quiet room at the children's school. Parents of all children gave written informed consent.

\subsection{Procedure}

In this research study, we used the UX Laddering method described above to benchmark children's user experiences with digital technologies[25]. Eight digital games were selected in view of some predefined research questions, that seemed interesting in the field of game design for preschoolers. For each element of interest, two games with contrasting features regarding this element, were selected. The first item related to the applied input device. Do preschoolers prefer to work on a tablet on the one hand or a laptop (with mouse and keyboard) on the other hand? For this comparison, the child played the same game, i.e. Angry Birds [18], on both devices. Next, two different fantasy worlds were compared. In order to avoid gender biases, two comparison pairs were formulated. The first pair contained a dress-up game i.e. Dora Dress-Up[10], and a game of skill, i.e. K3 and the Ice Princess - Frog Game: Catching Frogs [23]. These games were in the first place marketed at girls and were both performed on a laptop. The next comparison pair contained two tablet games, that might appeal more to boys: a construction game, i.e. Toca Robot $\mathrm{Lab}[24]$, and a race game, i.e. Drawrace[14]. Finally, we wanted to elucidate which narrative progression structure children prefer. Therefore two laptop games with a similar fantasy world were compared: a more linear adventure game, i.e. Putt-Putt [5], and a learning game with a hub world of different mini-games, i.e. Clifford [20]. Consequently, four comparison pairs were obtained, which invited the child to make relative comparisons and judgments between two technologies[4].

\section{METHOD}

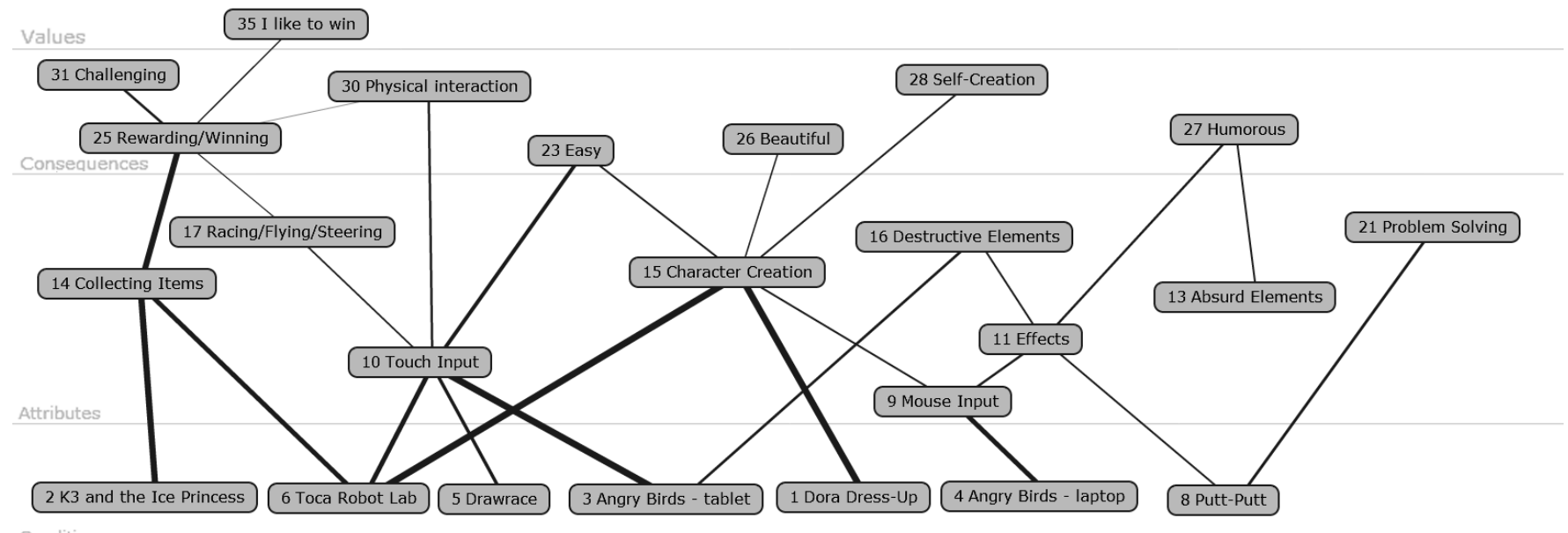

Conditions

Figure 3. The Hierarchical Value Map of this UX Laddering study with preschoolers: an overview of meaningful linkages across attributes, consequences and values of games. 
According to UX Laddering, we distinguished the following successive phases with the preschoolers: the product interaction phase, the preference ranking phase and the interview phase. In the product interaction phase, we provided the child with a meaningful context for the user experience evaluation. The child could explore the eight different games, that were preselected by the researcher. All games were played for about five to ten minutes. All children played these four comparison pairs in a fixed order. Within each pair, the two games were counterbalanced to avoid order effects. A facilitator was present in the room to guide the child through the gaming-part and to indicate when to change game.

In the preference ranking phase, the child was asked individually to judge preferences on user experiences of the eight digital computer games. Therefore, the child was successively presented the four comparison pairs. Screenshots of the two games were presented in order to stimulate the child's memory, whereupon a second facilitator prompted the child to identify his preferred game out of two. Next, in the interview phase, answers were validated through a Laddering interview. By probing several 'Why?'-questions, the second facilitator stimulated the child to climb up the ladder. As we worked with preschoolers, we did not strive to attain the value level. This is in line with the advice of Zaman and Vanden Abeele, who suggest to use attributeelicitation rather than value-elicitation techniques for UX evaluations with young children[30]. When the child showed difficulties to answer the question (e.g. silence, repeating his or her answers ...) the interview was finished. This procedure was applied for all eight digital games or four contrasts, until four preferred games were elicited (see Figure 4). From these four games, two new comparison pairs were formulated, dependent on the game features. Again the child was asked to identify his preferred game, followed by a Laddering interview, which resulted in two preferred games (4 and 7). These were in turn compared by the child, so that the ultimate favorite game out of eight was declared (4). According to the choices of the children, also other interesting pair comparisons were presented to the child, e.g. the girlish dress-up game versus the boyish construction game (the dashed line in Figure 4). Next to this verbal input, interesting information was also obtained from careful observations.

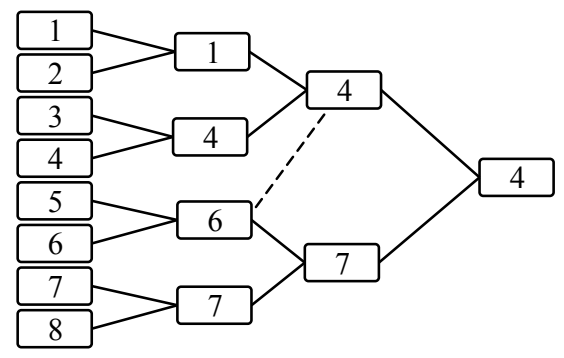

Figure 4. Example of preference ranking

\subsection{Qualitative Data Analysis}

The product interaction, preference ranking and laddering interviews were recorded on camera and all interviews were transcribed. Next, the transcriptions of these interviews were analysed to establish the core elements (attributes, consequences and values) from the interviews. The interviews were analysed by four of the authors of this research paper in a way that each interview was analysed by two different persons independently. Each author created a list of core elements, independent of the other authors. Next, these four lists of core elements were compared to each other and refined into one set of core elements that all researchers agreed on. This final list of core elements is depicted below in Table 3, followed by its Popularity, Centrality and Prestige [13]. These three indices reflect the importance or prominence of the elements in the HVM structure. The higher the score, the more often the element is involved in connections with other elements in the HVM. Popularity represents the sum of ingoing links (how often another element leads to this element) plus the out-going links (how often this element links to another element). Centrality is the proportion of popularity over the total of links. Prestige is the proportion of in-going links only, over the total of links.

In total, we discerned eight conditions (i.e. the games), fourteen attributes, ten consequences and six values. Conditions 1-8 refer to the answer on the ranking questions and indicate the game that was preferred most. Attributes 9-22 are the perceived qualities or features of the games, independent of the judgment of the individual child. These attributes were mentioned by the children in their explanation of the preference.

Table 3. A list of the core elements, followed by its Popularity, Centrality and Prestige

\begin{tabular}{|c|c|c|c|}
\hline \multicolumn{4}{|c|}{ Conditions } \\
\hline 1 & Dora Dress-up & 5 & Drawrace \\
\hline 2 & K3 and the Ice Princess & 6 & Toca Robot Lab \\
\hline 3 & Angry Birds - tablet & 7 & Clifford \\
\hline 4 & Angry Birds - laptop & 8 & Putt-Putt \\
\hline \multicolumn{4}{|c|}{ Attributes } \\
\hline 9 & Mouse Input (53|.09|.04) & 16 & Destructive Elements (46|.08|.05) \\
\hline 10 & Touch Input (70|.12|.05) & 17 & Racing/Flying/Steering (60|.10|.08) \\
\hline 11 & Effects (51|.09|.04) & 18 & Visceral Attraction (5|.01|.00) \\
\hline 12 & Fantasy Elements (24|.04|.02) & 19 & Variation (21|.03|.03) \\
\hline 13 & Absurd Elements (15|.02|.01) & 20 & Familiar from home (14|.02|.02) \\
\hline 14 & Collecting items (61|.10|.05) & 21 & Problem Solving (23|.04|.03) \\
\hline 15 & Character Creation (68|.11|.08) & 22 & Duration (9|.01|.01) \\
\hline \multicolumn{4}{|c|}{ Consequences } \\
\hline 23 & Easy (59|.10|.09) & 28 & Self-Creation (23|.04|.03) \\
\hline 24 & Difficult (5|.01|.01) & 29 & Learning $(4|.01| .00)$ \\
\hline 25 & Rewarding/Winning (63|.11|.09) & 30 & Physical interaction (27|.04|.04) \\
\hline 26 & Beautiful (26|.04|.04) & 31 & Challenging (47|.08|.08) \\
\hline 27 & Humorous (33|.05|.05) & 32 & Social interaction $(1|.00| .00)$ \\
\hline \multicolumn{4}{|c|}{ Values } \\
\hline 33 & I like to move (3|.09|.04) & 36 & I like to choose $(1|.00| .00)$ \\
\hline 34 & I like to act crazy $(1|.00| .00)$ & 37 & Belonging (6|.01|.01) \\
\hline 35 & I like to $\operatorname{win}(7|.01| .01)$ & 38 & I like to perform tasks $(2|.00| .00)$ \\
\hline
\end{tabular}

Consequences 23-32 are related to both the use of the product and judgment of the child. Finally, six values were derived. These values are independent of the specific product use. They relate to relatively stable beliefs or cognitions, defined solely by the individual. 
Next, the interviews were re-analysed and coded by the four authors independently on the basis of this new list of core elements. Again, every interview was analysed and coded by two different persons. On the basis of this second resulting data set, inter-reliability between coders was assessed. Cohen's Kappa was found to be at 0.97 , demonstrating a very high level of agreement between coders. A typifying example of a transcribed Laddering interview is shown in Table 4. As can be derived from the interview, the ladder contained in the interview starts from the attribute "collection of items" leading to the consequence "rewarding/winning", and finally to the value "I like to win".

Table 4. Example of an excerpt of a Laddering interview between the facilitator $(F)$ and child $(C)$

F: 'Show me which game was most fun?' (K3 and the Ice Princess vs. Dora Dress-Up)

C: 'This one' (child points towards K3and the Ice Princess)

Condition: $K 3$ and the Ice Princess

F: 'Why do you prefer this game?'

C: 'Because I had caught three frogs, almost four'

Attribute: Collection of items

F: 'Can you tell me why you like to have a lot of frogs?'

C: 'Because then I win'

Consequence: Rewarding/Winning

F: 'Why do you like that?'

C: 'I don't like to lose'

Value: I like to win

\subsection{Quantitative Data Analysis}

After finishing the qualitative data analysis, a quantitative analysis was performed. First, all ladders were coded on the basis of the above list of core elements and entered into Ladderux[18], an online tool designed for the quantitative analysis of user experience Laddering data. The coding of the ladders was summarized in a Score Matrix $\left(\mathrm{SM}^{2}\right)$, that lists up all ladders for all individual respondents. In total, the SM consisted out of 204 ladders for 25 preschoolers.

After the reconstruction of all ladders, an Implication Matrix $\left(\mathrm{IM}^{2}\right)$ was created, that summarizes the amount of direct and indirect links between two elements in the ladders. A direct link occurs when two elements follow one another directly within one ladder. An indirect link refers to two elements that are positioned in the same ladder, but that are not adjacently.

Contrary to the SM, the IM presents Means-End Chains (MEC's) at the aggregate level instead of ladders the individual level. The IM resulted in a total number of 602 links ( 374 direct and 228 indirect links). As the focus lies on the relations that were regularly mentioned as meaningful over all respondents, a cut-off level was defined. Only links with strengths that reached the cut-

${ }^{2}$ In order to respect page limitations, the following data has not been inserted in this paper but can be inspected online at http://www.ladderUX.org/DYSL-X/IDC2013/ off level were kept as they represent a dominant way of thinking, present among the majority of preschoolers. To determine the appropriate cut-off level, one looks for that number that leads to the most informative and interpretable solution, yet retains the most information. Consequently, for the conditions, attributes, consequences and values, we chose a cut-off level of respectively seven, four, two and four [16]. This resulted in 195 of the 602 links.

As a final step, these remaining dominant relationships were mapped out in a Hierarchical Value Map (HVM, see Figure 3). The HVM summarizes the dominant links in a graphical way and hereby reveals which games (conditions) and important attributes (at the bottom) link to the above consequences and values. The thickness of the lines between two elements represents the link strength showed in the IM.

From these results, we deduce a number of design recommendations for game designers with regards to this preschool audience. In other words, we present a set of game mechanics and dynamics that can help designers to fulfill the targeted aesthetics as presented in the MDA framework.

\section{RESULTS AND DESIGN GUIDELINES}

Based on the obtained HVM, four major (links between) core elements can be deduced, which reflect what the majority of preschoolers like when playing digital games.

\subsection{Collecting Things $>>$ Rewards/Winning $>>$ Challenging}

The element 'Rewards/Winning' seems to be a very important prerequisite for preschoolers to like a game. With a centrality factor of 0.11 and a prestige factor of 0.09 , it is an important element in our HVM. As shown in Figure 3, 'Rewards/Winning' is considerably linked to the element 'Challenging' ( 3 direct and 1 indirect link) and to the value 'I like to win' ( 3 direct links). The element 'Challenging' has a prestige factor of 0.08 . In other words, the link between 'Rewards/Winning' and 'Challenging' seems to be of major importance when creating enjoyable games for preschoolers. Mapping this onto the MDA framework, these elements could be classified under the aesthetic 'Challenge'.

When looking at existing games for preschoolers, a typical way to introduce challenge is by implementing goals and obstacles that require some form of problem solving (e.g. matching shapes, learning words, arithmetic's etc.). However, in our HVM the element 'Problem Solving' does not connect to the element 'Rewards/Winning' at all. Instead, 'Rewards/Winning' is reached by a stronger link starting from the attribute 'Collecting Things' (7 direct links and 1 indirect link). So our results suggest that the underlying mechanic of collecting things is more important and more fun for preschoolers than the mechanic of solving problems.

To summarize, preschoolers enjoy the collection of different items through the game as they serve as a reward system. As illustrated in the following interview-extract, this gives them a sense of victory (Interview 1) and ultimately realizes a challenging gameplay-experience. 


\section{Toca Robot Lab}

C: You had to collect three stars.

F: Did you enjoy that?

C: Yes.

F: Why do you like to collect three stars?

$\mathrm{C}$ : Because you win.

In the present study, the attribute 'Collecting things' was implemented in different ways: by catching jumping frogs (K3 and the Ice Princess) or by collecting stars while flying through the sky (Toca Robot Lab). There's a subtle nuance between both games. Collecting the jumping frogs involves catching moving targets, whereas collecting the stars requires the player to navigate over stationary targets, much like Mario collects his coins. Another possibility to implement the attribute 'Collecting things' is through a more direct way, where the player has to collect a certain set of objects to "complete" his collection, like finding a set of different-colored diamonds or finding all the pieces of an avatars outfit.

Additionally, from our observations, we note that collecting things one piece at a time provides some excellent short term reward, while completing a full set is a long-term reward which gives them a sense of accomplishment and victory.

\subsection{Touch Input vs. Mouse Input}

One of the contrasts we presented in this study related to the preferred input device. Consequently, preschoolers were offered games with touch input (via an iPad) as well as games with traditional mouse input. The Implication Matrix shows that the element 'Touch Input' is more frequently mentioned than the element 'Mouse Input' (38 times vs. 29 times), resulting in the highest centrality factor of all elements $(0.12)$. 'Touch Input' leads to the attribute 'Easier' with 8 direct links and 2 indirect links (Interview 2). In fact, this contributes to 'Easier' having the highest prestige factor (0.09) of all elements.

\section{Angry Birds - tablet}

F: Why did you prefer to use your finger, instead of a computer mouse?

$\mathrm{C}$ : Because it was easier.

F: What makes you think that was easier?

$\mathrm{C}$ : Working with the mouse is harder, because of the cables.

'Mouse input' is only indirectly connected to 'Easier', and more specifically via the element 'Character Creation' (Figure 3). This makes us question if it is not more the inherent mechanical simplicity of dress-up games, rather than the actual input method which causes that link.

Furthermore, 'Touch Input' is connected to the consequence 'Physical Interaction' through five direct links. This shows that preschoolers like the intuitiveness of the physical interaction with their hands and fingers. In the games we presented, concrete implementations of 'Physical Interaction' could be interpreted as pulling the catapult in Angry Birds, making the flying robot follow your finger in Toca Robot Lab, or drawing the best possible driving path in Drawrace (Interview 3).

\begin{tabular}{l}
\hline 3. Drawrace \\
F: Why did you enjoy this racing game? \\
C: Because I had to draw a line. \\
F: What did you like about drawing a line? \\
C: I liked to use my finger when drawing. \\
\hline
\end{tabular}

In relation to the MDA framework, implementing a mechanic of intuitive touch based control can contribute to achieving the aesthetic 'Sense-Pleasure'.

\subsection{Character Creation}

With a centrality-factor of 0.11 , 'Character Creation' appears to be the second most dominant element in our study and is found with almost all children (22 out of 25). As illustrated in Figure 3, 'Character Creation' connects to a range of different consequences. First, 'Character Creation' directly connects four times to 'Easier', which means that the preschoolers are not always looking for challenging gameplay (Interview 4).

\section{Toca Robot Lab \\ F: What do you like about the robot game? \\ C: I like it because I could make a robot. \\ F: Why do you like making a robot? \\ C: Because it's easy to do.}

Four direct links are also found with the obvious consequence 'Self-creation' (Interview 5). Character creation is often implemented by providing a standard avatar, which can be outfitted with different clothes and accessories. This was the case for the Dora Dress-Up game, where children had to pick out clothes they liked and make a pretty ensemble. Hence they could create their own appealing character, which is the reason why 'Character Creation' also connects to 'Beautiful' (3 direct links and 1 indirect link, Interview 5). In the case of Toca Robot Lab, character creation was realized by creating a robot from scratch by combining different robot-parts. In other games, the concept of character creation can be extended to the customization of all kinds of objects, e.g. vehicles, houses etc. In relation to the MDA framework, playing around with different possibilities of customization provides a way of 'Self Expression'.
5. Dora Dress-Up
F: Tell me, why do you prefer this game?
C: You can choose yourself which clothes you want to put on.
F: Why do you like that?
$\mathrm{C}$ : Because there are a lot of different clothes.
F: What do you like about these clothes?
C: I like that they are beautiful. 


\subsection{Humorous, Destructive, Absurd and Visceral Effects}

Lastly, we would like to discuss a cluster of interwoven elements, rather than a clear unidirectional chain, around the central element 'Effects'.

First, we notice a strong link with 'Mouse Input' (5 direct links and 1 indirect link). This connection is probably explained best by the action-reaction effect that some games implemented. The user uses the mouse to click on an object and in reaction to this motion something happens. This reaction usually has the form of special sound and/or visual animation effects. In our study, a typical example is found in Putt-Putt. In this game the player clicks on a dog, who then barks to scare away a rat that was blocking the way. 'Effects' like this are usually enjoyed by preschoolers, because they are perceived as 'Humorous' (5 direct links, Interview 6).

\section{Putt-Putt \\ F: Why do you prefer Putt-Putt? \\ C: I liked to scare the little animal. \\ F: Why? \\ C: Because I think that's funny.}

A second link is observed from 'Effects' to 'Destructive Elements' (4 direct links). A lot of preschoolers seem to enjoy the appearance of destructive elements in games, e.g. cutting out the enemy by destroying the castle in Angry Birds (Interview 7).

\section{Angry Birds - tablet}

C: I liked it when the green pigs fell and the wooden tower cracked.

F: Why did you like that?

C: Because they fell down and said 'boom' (...) I could hear that.

F: Why did you like to hear the 'boom'?

C: Because it was funny.

In reference to the MDA framework, the use of these visceral effects and visual gags can contribute to the aesthetic 'SensePleasure' when working with preschoolers.

As a side-note, the HVM also shows a connection between 'Absurd Elements and 'Humorous' (4 direct links). When preschoolers were asked to explain why something was humorous, they often referred to absurd and ludicrous elements within the game (Interview 8). This confirms that preschoolers have a sense of how things should be in reality and find it humorous when things deviate from the norm.
8. Clifford
F: Tell me, what do you like about the dog Clifford?
C: I see that he had paint on his butt.
F: Why do you like that?
C: Because it's funny.

\section{FUTURE WORK AND DISCUSSION}

Although the present study yields some interesting guidelines in the field of game design for preschool children, we must be critical regarding the obtained results.

First, this study was part of a larger study aiming at developing games for preschoolers on tablets. Therefore, the eight games of our study were preselected in function of our research questions. By presenting the child some predefined comparison pairs, we implicitly guided the interview in function of different research questions (e.g. the preference for a certain input style). Consequently, the child's answers were inevitably pushed in a certain direction. In other words, the selection of games was biased and the obtained results will be colored by this game selection. When examining the frameworks previously described, we notice that two elements weren't included in the presented game contrasts: (1) fellowship or social interaction and (2) submission or diversion (playing to waste time). With respect to the first element, only single player games were selected in the present study. Children were ought to play all games alone, without interacting with classmates. Second, these games were presented in a testing context. As children were more or less obliged to play the preselected games during a predefined period, there was no room for gameplay as pastime. Consequently, these two factors, fellowship and submission, were not found in our results. Therefore, conclusions suggesting that both elements do not contribute in the explanation why preschoolers play games might not be valid. Moreover, although only single player games were selected, we did observe interactions between classmates when playing the same game simultaneously, e.g. comparing results or helping each other when bumping into unexpected problems. This implies that social interactions do play a role in preschoolers' game experience. To conclude, the methodology used in the present study does not suffice in inquiring all aesthetics that are believed to be important for meaningful gameplay.

A second critical reflection relates to the appearance of gender differences in preschoolers' behavior. By preschool age, children start to identify themselves as being male or female, which leads to gender related preferences (for an overview, see [1]). Consequently, it is reasonable that girls and boys mention different elements in explaining their game preferences. Unfortunately, because of the rather limited sample size $(\mathrm{N}=25)$ and an uneven distribution of boys and girls (15 boys and 10 girls) in this study, no clear gender distinctions could be made. Nevertheless, we noticed some differences between girls and boys. Regarding 'Character Creation' we noticed two groups. The first group, children who were only attracted to the dress-up game (i.e. Dora Dress-Up), comprised mainly girls: 3 boys (20\% of all boys) and 4 girls ( $40 \%$ of all girls). Boys on the other hand seemed to be more represented in the second group ( 6 boys or $40 \%$ of all boys vs. 1 girl or $10 \%$ of all girls), that preferred the construction game (i.e. Toca Robot Lab). Also the following retrieved core elements were more mentioned by boys then by girls in the account of their preference choice: 'Problem Solving' ( 7 boys or $47 \%$ of all boys vs. 3 girls or $30 \%$ of all girls), 'Destructive Elements' ( 9 boy or $60 \%$ of all boys vs. 4 girls or $40 \%$ of all girls) and 'Racing/Flying/Steering' (13 boys or $87 \%$ of all boys vs. 6 girls or $60 \%$ of all girls). 
These differences suggest a tendency for gender differences in preferred game experiences. However, as mentioned before, the limited sample size used in the present study does not allow us to draw valid conclusions on this issue.

Finally, we reflect on the effectiveness of the Laddering method, in order to unveil preschoolers' game gratifications and game attributes. Zaman and colleagues [25,30]suggested that Laddering is possible with preschoolers from five year old and onwards and put forward that "with 45 preschoolers and 5 elements $^{3}$, the research study should in total provide 225 elements". Our study confirms the suggestion that five-year-olds can generate meaningful ladders. The mean age of our sample of preschoolers was 66 months (SD $=4$ months). In total 25 preschoolers generated 578 elements in total, with 8,16 ladders generated per child. Hence, the preschoolers in our sample did not generate 5 but rather 23,12 elements on average. These numbers are substantially higher than the numbers put forward by Zaman et al. We hypothesize that a higher average age and a wider sample of games might be the reason for the higher number of ladders generated in our study. Zaman et al. chose only 3 different games to be experienced by preschoolers, we relied on a selection of eight different games, that were offered in pairs in 7 iterations of preference ranking. Clearly, further work is necessary to investigate the effect of the specific attribute elicitation methods (in or case preference ranking, via seven iterations) on the number of generated ladders and elements.

However, we also note that Laddering, while insightful, is timeconsuming compared to other methods. A rough estimation is that we spend approximately 150 hours on the laddering study. Interviewing and transcribing 25 preschoolers already takes time, and only then the actual analysis can take place. Even with software tools that aid with the quantitative analysis, Laddering might be (too) time consuming within the scope of a game design and development process. Therefore, in order to move the method forward, we believe that further efforts must be made to automate part of the process. A further look into hard laddering (a variation of the laddering technique with greater structuring in data collection as the respondent is forced to produce ladders one by one, and obliged to give answers in such a way that the sequence of the answers reflects increasing levels of abstraction)[12, 28]might resolve some of these practical limitations of Laddering research.

\section{CONCLUSION}

In this paper we presented a Laddering study with 25 preschoolers, aimed at unveiling the playing motives of preschoolers. Our study confirms that Laddering with five-yearolds is feasible and a valid means of investigating player motivations. Our results point to the following design guidelines on how to design for specific aesthetics/gratifications presented in table 5. It is our aspiration that these guidelines can guide game designers when designing games for five-year olds.

\footnotetext{
${ }^{3}$ One element is one attribute, consequence or value mentioned in a specific ladder, e.g. a study with two ladders of each three elements would total 6 elements.
}

Table5. An overview of design guidelines

\begin{tabular}{|c|c|}
\hline $\begin{array}{l}\text { Aesthetics/ } \\
\text { gratifications }\end{array}$ & $\begin{array}{c}\text { Mechanics/ } \\
\text { attributes }\end{array}$ \\
\hline - Challenge & $\begin{array}{l}\text { Implement "challenge" via collecting different items } \\
\text { through the game. This can equally serve as a } \\
\text { reward system and provides preschoolers with a } \\
\text { sense of victory. }\end{array}$ \\
\hline $\begin{array}{l}\text { - Sense-Pleasure } \\
\text { - Arousal } \\
\text { - Body and } \\
\text { senses }\end{array}$ & $\begin{array}{l}\text { Address "body \& senses" via intuitive touch-based } \\
\text { controls that rely on physical movement of the } \\
\text { fingers, with natural mappings (i.e. analog to } \\
\text { movement in real life). } \\
\text { Implement visceral effects and visual gags, } \\
\text { destructive elements (exploding items, breaking } \\
\text { walls,...). }\end{array}$ \\
\hline $\begin{array}{l}\text { - Expression } \\
\text { - Creative and } \\
\text { constructive } \\
\text { expression }\end{array}$ & $\begin{array}{l}\text { Allow for creative expression via character creation } \\
\text {, providing a standard avatar, which can be } \\
\text { outfitted with different clothes and accessories. } \\
\text { This can be extended to the customization of all } \\
\text { kinds of objects, e.g. vehicles, houses etc. }\end{array}$ \\
\hline - Humor & $\begin{array}{l}\text { Insert humor via deviating from the norm, } \\
\text { preschoolers already have a sense of how things } \\
\text { should be in reality. }\end{array}$ \\
\hline
\end{tabular}

\section{ACKNOWLEDGMENTS}

We like to thank the teachers and preschoolers of Heilig Hart Heverlee, Scholengemeenschap De Kraal and Sint-Jan Berchmanscollege Diest who participated in our experiment with great enthusiasm.

\section{REFERENCES}

1. Aubry, S., Ruble, D.N., and Silverman, L.B. The role of gender knowledge in children's gender-typed preferences. In L. Balter C. S. Tamis-LeMonda, ed., Child psychology: A handbook of contemporary issues. Psychology Press, New York, NY, US, 1999, 363-390.

2. Gould, J.D. and Lewis, C. Designing for usability: Key principles and what designers think,. Communications of the ACM 28, 1985, 300-311.

3. Gutman, J. A means-end chain model based on consumer categorization processes. Journal of Marketing 46, 2 (1982), 60-72.

4. Hanna, L., Neapolitan, D., and Risden, K. Evaluating computer game concepts with children. Proceedings of the 2004 conference on Interaction design and children: building a community, ACM (2004), 49-56.

5. Humongous Entertainment. Putt-Putt 3: De Autostad 500. Humongous Entertainment, Bothell, Washington, 1998.

6. Hunicke, R., Leblanc, M., and Zubek, R. MDA: A formal approach to game design and game research. 19th National Conference of AI, (2004), 1-5.

7. International Organization for Standardization. ISO 13407:1999 - Human-centred design processes for interactive systems. http://www.iso.org/iso/catalogue_detail.htm?csnumber=2119 7.

8. Jans, G. and Calvi, L. Using Laddering and Association Techniques to Develop a User-Friendly Mobile (City) 
Application. In On the Move to Meaningful Internet Systems 2006: OTM 2006 Workshops. 2006, 1956-1965.

9. Leitner, M., Wolkerstorfer, P., Sefelin, R., and Tscheligi, M. Mobile multimedia: identifying user values using the meansend theory. Proceedings of the 10th international conference on Human computer interaction with mobile devices and services, ACM (2008), 167-175.

10. Nick Jr. Dora Dress-Up. Viacom International Inc, USA, New York.

11. Palmgreen, P. and Rayburn, J.D. Gratifications sought and media exposure: An Expectancy Value Model. Communication Research 9, 4 (1982), 561-580.

12. Phillips, J.M. and Reynolds, T.J. A hard look at hard laddering: A comparison of studies examining the hierarchical structure of means-end theory. Qualitative Market Research: An International Journal 12, 1 (2009), 83-99.

13. Pieters, R., Baumgartner, H., and Allen, D. A means-end chain approach to consumer goal structures. International Journal of Research in Marketing 12, 3 (1995), 227-244.

14. Redlynx Ltd. Drawrace. Chillingo, Finland, Helsinki, 2009.

15. Reynolds, T.J. and Gutman, J. Laddering theory, method, analysis, and interpretation. In T.J. Reynolds and J.C. Olsen, eds., Understanding consumer decision making: the meansend approach to marketing and advertising strategy. Lawrence Erlbaum, Mahwah N.J. ;:London, 2001, 25-52.

16. Reynolds, Thomas J., Dethloff, C., and Westberg, S.J. Advancements in Laddering. In Understanding Consumer Decision-Making: The Means-end Approach to Marketing and Advertising Strategy, eds Reynolds, T.J., Olson J.,C. Lawrence Elbaum Associates, New Jersey, 2001, 91-118.

17. Rideout, V. Zero to Eight: Children's Media Use in America. Common Sense Media, 2011.

18. Rovio Entertainment. Angry Birds. Chillingo, Finland, Espoo, 2009.

19. Salen, K. and Zimmerman, E. Rules of Play: Game Design Fundamentals. MIT Press, 2003.

20. Scholastic Interactive. Clifford the Big Red Dog Learning Activities. Scholastic Interactive, USA, New York, 2001.
21. Sherry, J.L., Lucas, K., Greenberg, B.S., and Lachlan, K. Video game uses and gratifications as predictors of use and game preference. Playing video games: Motives, responses, and consequences, (2006), 213-224.

22. Shuler, C. iLearn II: An Analysis of the Education Category on Apple's App Store. Joan Ganz Cooney Center, New York, $\mathrm{NY}, 2012$.

23. Studio 100. K3 en het Ijsprinsesje. Studio 100, Belgium, Schelle, 2006.

24. Toca Boca. Toca Robot Lab. Toca Boca, Sweden, Stockholm, 2011.

25. Vanden Abeele, V., Zaman, B., and De Grooff, D. User eXperience Laddering with preschoolers: unveiling attributes and benefits of cuddly toy interfaces. Personal and Ubiquitous Computing, (2011).

26. Vanden Abeele, V. and Zaman, B. The Extended Likeability Framework: A Theoretical Framework for and a Practical Case of Designing Likeable Media Applications for Preschoolers. Advances in Human-Computer Interaction 2008, Article ID 719291 (2008), 11.

27. Vanden Abeele, V. and Zaman, B. Laddering the user experience! User Experience Methods, Interact 2009, Uppsala, Sweden, (2009).

28. Veludo-de-Oliveira, T.M., Ikeda, A.A., and Campomar, M.C. Laddering in the practice of marketing research: barriers and solutions. Qualitative Market Research: An International Journal 9, 3 (2006), 297-306.

29. Zaman, B. and Vanden Abeele, V. Towards a likeability framework that meets child-computer interaction \& communication sciences. Proceedings of the 6th international conference on Interaction design and children - IDC '07, (2007), 1-8.

30. Zaman, B. and Vanden Abeele, V. Laddering with Young Children in User eXperience Evaluations: Theoretical Groundings and a Practical Case. Interaction Design and Children, (2010).

31. Zaman, B. Introducing contextual laddering to evaluate the likeability of games with children. Cognition, Technology \& Work 10, 2 (2007), 107-117. 